\title{
Differential Modulation of $\gamma$-Aminobutyric Acid Receptors by Caprolactam Derivatives with Central Nervous System Depressant or Convulsant Activity
}

\author{
J. H. SKERRITT ${ }^{1,3}$, G. A. R. JOHNSTON 1 , S. CHEN CHOW ${ }^{1}$, R. L. MACDONALD ${ }^{3}$, R. H. PRAGER ${ }^{2}$ and A. D. WARD ${ }^{2}$ \\ ${ }^{I}$ Department of Pharmacology, University of Sydney, N.S.W. 2006, ${ }^{2}$ Department of Organic Chemistry, University of Adelaide, \\ S.A. 5001 (Australia) and ${ }^{3}$ Department of Neurology, University of Michigan, Ann Arbor, MI 48109 (U.S.A.)
}

(Accepted July 10th, 1984)

Key words: $\gamma$-aminobutyric acid receptors — caprolactam derivatives — central nervous system depressants — seizures

\begin{abstract}
The effects of a series of caprolactam derivatives with central depressant, convulsant or muscle relaxant activity were investigated upon $\gamma$-aminobutyric acid (GABA) receptor-ionophore binding to rat brain membranes uijing $\left[{ }^{3} \mathrm{H}\right] \mathrm{GABA},\left[{ }^{3} \mathrm{H}\right] \mathrm{muscimol}$ and $\left[{ }^{35} \mathrm{~S}\right]-$ tert.-butylbicyclophophorothionate ([ $\left.\left.{ }^{35} \mathrm{~S}\right] \mathrm{TBPS}\right)$ as ligands, and GABA responses in mouse spinal cord neurones in dissociated cell culture. Some caprolactams produced a picrotoxin-like chloride-dependent partial inhibition of muscimol binding and were potent inhibitors of TBPS binding. One compound that was further investigated (4,4,6,6-tetramethylhexahydro-2H-azepin-2-one), inhibited GABA responses and increased the frequency of paroxysmal depolarizations in cultured neurones. Other caprolactams enhanced muscimol binding and were relatively weak inhibitors of TBPS binding, and one (3,3-diallyl-6,6-dimethylhexahydro-2H-azepin-2,4dione) was shown to enhance GABA responses and produced quiescence of activity in cultured neurones. There was a direct correlation between caprolactam effects on muscimol binding in the presence of chloride ions and their effects on TBPS binding suggesting a similar site of action for the caprolactams influencing the binding of these two ligands. For the two classes of caprolactams, with respect to inhibition or enhancement of muscimol binding, there appeared to be a relationship between in vitro effects and their convulsant or depressant activity in mice. Caprolactams may be useful low molecular weight probes for the study of GABA receptor-ionophore complexes.
\end{abstract}

\section{INTRODUCTION}

A large number of sedative or convulsant drugs contain a substituted lactam system. Examples include drugs with 5-(phenytoin, ethosuximide), 6(barbiturates, glutarimides, primidone and methyprylon) and 7-membered ring systems (various benzodiazepines). Caprolactam (hexahydro-2H-azepin2-one), the simplest 7-membered ring lactam has convulsant activity in high doses ${ }^{3}$. This activity was found to be increased by alkylation (especially methylation) at various positions, in particular at carbons 4 and 6 of the lactam ring 2,5 . Some other caprolactams, however, such as those with large alkyl substituents at carbon 7 have sedative activity in mice ${ }^{2}$.

There iselectrophysiological evidence to suggest that the convulsant caprolactams may be acting as $\gamma$ aminobutyric acid (GABA) antagonists? . Little, however, is known about the mode of GABA antagonism by these caprolactams. GABA antagonists may be grouped into two main classes: (1) those acting upon the GABA recognition site, such as bicuculline; and (2) those blocking GABA-activated chloride ion fluxes at GABA receptor coupled chloride channels, e.g. picrotoxin (reviewed in Johnston et al.6) and tert.-butylbicyclophosphorothionate (TBPS) ${ }^{19}$. Recently, incubation conditions have been identified whereby both bicuculline-like and picrotoxin-like agents may affect in vitro GABA binding to brain membrane preparations ${ }^{21}$. In the presence of physiological concentrations of chloride ions and at room temperature or above, picrotoxin and related convulsants produced a potent but partial inhibition of GABA binding to rat brain membranes. In contrast, both agonists and antagonists at the GABA recognition site fully inhibited binding either in the presence or absence of chloride ions ${ }^{4}$. Several groups have demonstrated a chloride-dependent enhancement of GABA receptor binding by barbiturates ${ }^{1,11,13,18,21,22,23}$. [35S]TBPS has been introduced

Correspondence: G. A. R. Johnston, Department of Pharmacology, University of Sydney, N.S. W., 2006, Australia. 
recently as a ligand with which to study specific sites coupled to GABA and chloride recognition sites ${ }^{19}$. A wide variety of drugs likely to interact with GABA receptor-ionophore complexes have been shown to inhibit TBPS binding ${ }^{19}$, whereas benzodiazepine agonists enhance TBPS binding 20 .

In the present experiments, the effects of pentobarbitone, picrotoxinin and several caprolactam derivatives with convulsant, sedative or muscle relaxant activity in mice, were examined upon the binding of radiolabelled GABA, muscimol and TBPS to rat brain membranes. The effects of two caprolactams were further examined upon spontaneous electrical activity and responses to iontophoretically applied GABA in mouse spinal cord neurones in dissociated cell culture. It is reported that various caprolactam derivatives can modulate GABA receptor binding and $G A B A$ responses in vitro, most probably at the level of GABA receptor-coupled chloride channels.

\section{MATERIALS AND METHODS}

Washed synaptosomal membranes were prepared from whole rat brains as previously described 17,18 . Briefly, whole brains of male Sprague-Dawley rats (10-12 weeks old) were homogenized in $0.32 \mathrm{M}$ sucrose and a $\mathrm{P}_{2}$ synaptosomal-mitochondrial pellet formed by differential centrifugation. This pellet was lysed in distilled water, and washed 8 times in $50 \mathrm{mM}$ Tris-citrate buffer $\mathrm{pH} 7.1$ at $2{ }^{\circ} \mathrm{C}$, and frozen $1-14$ days. On the day of assay, membranes were washed 4 times in incubation buffer, $20 \mathrm{mM}$ potassium phosphate, pH 7.5 at $25^{\circ} \mathrm{C}$ which contained $120 \mathrm{mM}$ potassium chloride unless otherwise indicated. [ $\left.{ }^{3} \mathrm{H}\right]$ muscimol $(9.3 \mathrm{Ci} / \mathrm{mmol}$, New England Nuclear) or $\left[{ }^{3} \mathrm{H}\right] \mathrm{GABA}(74.5 \mathrm{Ci} / \mathrm{mmol}$, New England Nuclear) binding assays were performed using $5 \mathrm{nM}$ radioligand incubated with washed synaptosomal membranes (ca. $0.5 \mathrm{mg}$ protein) and the test drug in $1 \mathrm{ml}$ volume. Incubations were at $25^{\circ} \mathrm{C}$ for $15 \mathrm{~min}$ and terminated by rapid centrifugation at $10,000 \mathrm{~g}^{18}$. Non-saturable binding of muscimol was determined using $100 \mu \mathrm{M}$ muscimol, and for GABA, using $1 \mathrm{mM}$ GABA.

TBPS binding was studied as described by Supavilai and Karobath ${ }^{20}$ using $2 \mathrm{nM}\left[{ }^{35} \mathrm{~S}\right] \mathrm{TBPS}(69 \mathrm{Ci} /$ mmol, New England Nuclear) with $200 \mathrm{mM}$ sodium chloride in $50 \mathrm{mM}$ Tris-citrate buffer, $\mathrm{pH} \mathrm{7.5, \text {at }}$
$23{ }^{\circ} \mathrm{C}$. Non-saturable binding was determined using $100 \mu \mathrm{M}$ picrotoxinin.

For electrophysiological studies cell cultures were prepared from spinal cords with attached dorsal root ganglia from 12-14-day-old mouse embryos, as described earlier ${ }^{14}$ and spinal cord neurones (7-8 weeks in vitro) were penetrated on the modified stage of an inverted phase-contrast microscope, using high resistance (25-40 M $\Omega$ ) glass micropipettes filled with either $4 \mathrm{M}$ potassium acetate $(\mathrm{KAc})$ or $3 \mathrm{M}$ potassium chloride $(\mathrm{KCl})$. Cultures were bathed in a phosphate buffered saline (composition in $\mathrm{mM}: \mathrm{NaCl}$ 143.4, $\mathrm{KCl} 4.2, \mathrm{CaCl}_{2} 0.9, \mathrm{MgCl}_{2} 1.0$ and glucose 5.6 in $9.5 \mathrm{mM}$ sodium phosphate buffer at $\mathrm{pH}$ 7.35-7.40). Using a conventional bridge circuit, simultaneous current injection and membrane potential measurement were made with a single recording micropipette; data were recorded on a 6-channel Gould polygraph.

For determination of spontaeous neuronal activity, spinal cord neurones (at $36^{\circ} \mathrm{C}$ ) were impaled using $\mathrm{KAc}$-filled electrodes and activity determined over a 3-min period. Normal spontaneous activity consisted of random firing of action potentials with an admixture of excitatory and inhibitory synaptic potentials ${ }^{9,15}$. Following determination of activity in 6-11 'control' cells, drugs were added to the bathing medium and activity determined in a further 4-15 cells.

In iontophoresis experiments, $10 \mathrm{mM} \mathrm{MgCl}$ was added to the bathing medium to suppress spontaneous activity, and the culture temperature was decreased slightly (to $33^{\circ} \mathrm{C}$ ) to prolong culture viability. GABA (0.5 M, pH 3.2) was applied iontophoretically to spinal cord neurones using $400 \mathrm{~ms}$ rectangular current pulses $(+0.5$ to $+20 \mathrm{nA})$ at 4 -s intervals. Drugs or vehicle $(0.1 \%$ or less dimethyl sulfoxide) were applied by miniperfusion $(0.2 \mathrm{psi}, 30 \mathrm{~s})$ from a pipette $15-100 \mu \mathrm{m}$ from the cell soma. Medium containing vehicle only did not alter responses to GABA. GABA responses ( $\mathrm{KCl}$ recordings) of 6-9 $\mathrm{mV}$ amplitude were evoked following membrane hyperpolarization to -80 to $-90 \mathrm{mV}$ and were used for assessment of drug actions. Data were accepted only if the amino acid responses returned to control levels within $5 \mathrm{~min}$ following removal of the drug-containing pipette from the vicinity of the cell under study. When KAc recording micropipettes were 


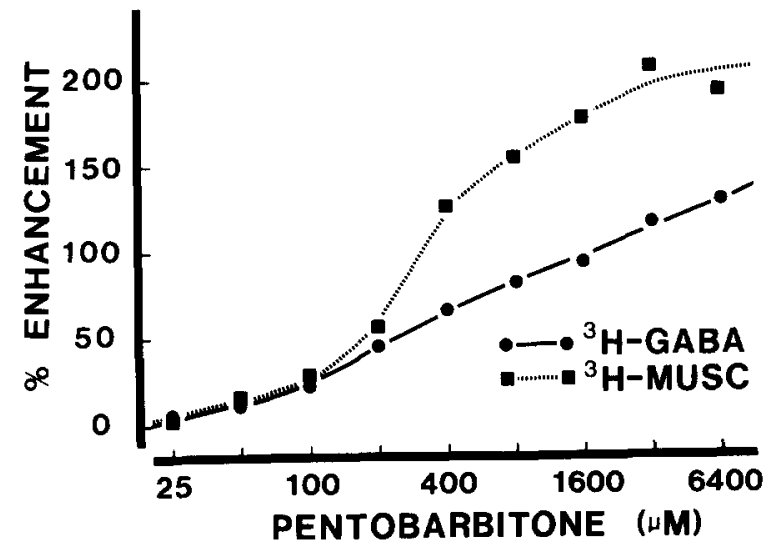

Fig. 1. Enhancement of GABA and muscimol binding by pentobarbitone. Data shown are from paired experiments performed in quadruplicate on two separate membrane preparations. Standard errors are omitted for clarity and did not exceed $10 \%$ of control for GABA binding and $6 \%$ of control for muscimol binding.

used, application of GABA produced membrane hyperpolarization and an increase in membrane con- ductance ${ }^{12}$. Use of $\mathrm{KCl}$-containing recording micropipettes allows chloride ions to enter the cell, changing the equilibrium potential for chloride ions from about $-65 \mathrm{mV}$ to $-20 \mathrm{mV}$, and GABA responses become depolarizing.

The pentobarbitone sodium used in the binding experiments was obtained from Abbotts, Australia, while that used in the electrophysiological experiments was purchased from Sigma, U.S.A. GABA (Sigma or Calbiochem), muscimol (Sigma) and picrotoxin (Sigma) were obtained commercially, while picrotoxinin was prepared by Dr. R. D. Allan. The syntheses of the caprolactams used have been published elsewhere $2,5,10$. Some of the caprolactams required dimethyl sulfoxide vehicle for solubilization (up to $0.1 \%$ in electrophysiological assays); in these cases paired control experiments with equal vehicle concentrations were always performed.

\section{TABLE I}

Chemical structures and pharmacological properties of the caprolactams studied

Conv, convulsant; Depr, depressant; Lmc, loss of muscle control; Lrr, loss of righting reflex; n.t., not tested.

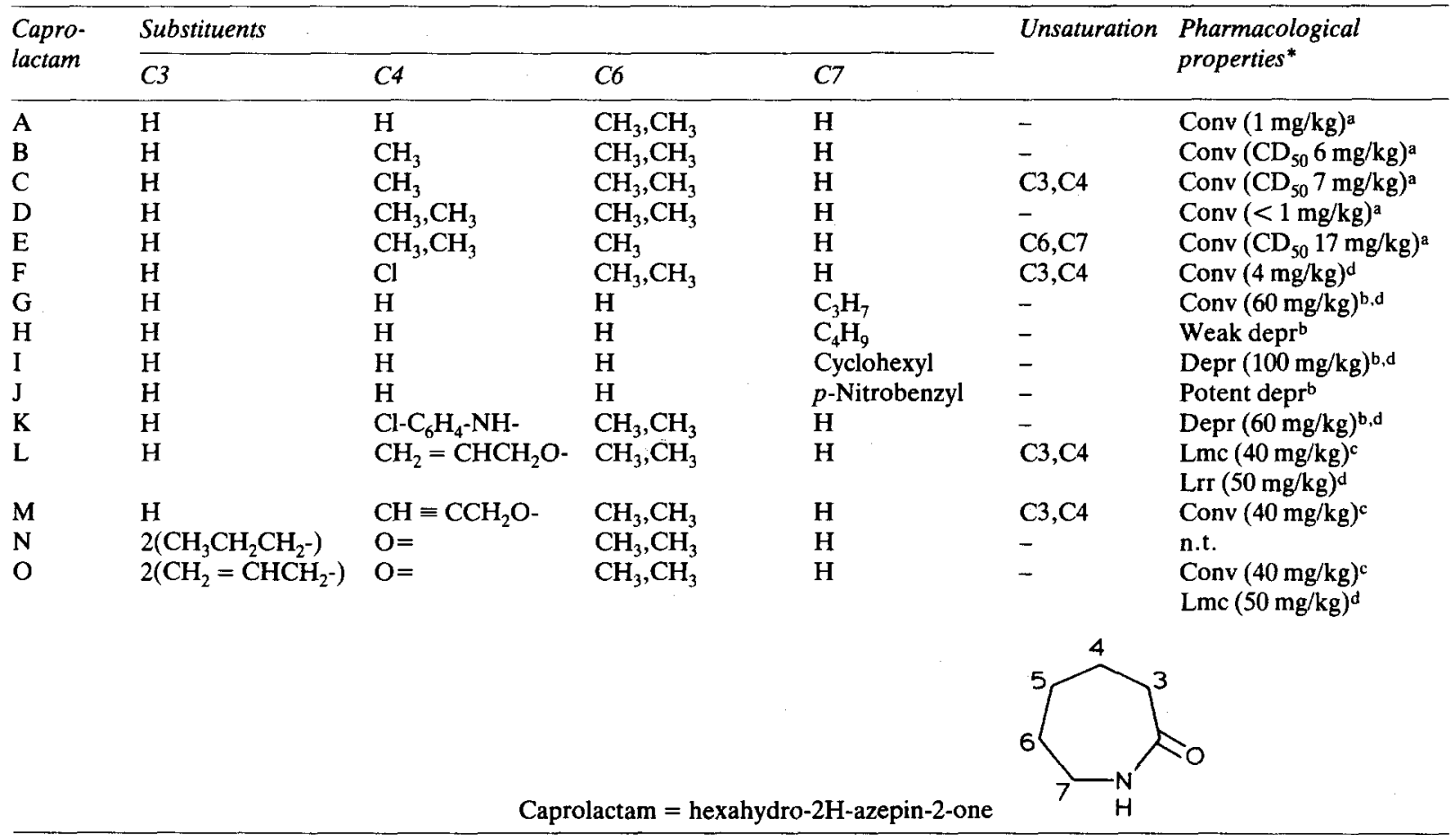

* Doses shown are for intraperitoneal injections into mice, either threshold doses or $\mathrm{CD}_{50}$ values if determined.

a Hutchison et al ${ }^{5}$; Duong et al. ${ }^{2}$; ${ }^{c}$ Mooney et al. ${ }^{10}$; d Ward, unpublished. 


\section{RESULTS}

Under the present assay conditions, pentobarbitone stimulated GABA and muscimol binding to rat membranes as previously observed ${ }^{18}$. Pentobarbitone was a slightly more potent enhancer of muscimol binding $\left(\mathrm{EC}_{50}=336 \pm 20 \mu \mathrm{M}\right)$ than of GABA binding $\left(\mathrm{EC}_{50}=428 \pm 23 \mu \mathrm{M}\right)$ and also produced greater maximal enhancement of muscimol binding at high barbiturate concentrations (Fig. 1). In contrast, picrotoxinin inhibited both GABA and muscimol binding. At $1 \mu \mathrm{M}$, picrotoxinin inhibited muscimol binding by $15.1 \%$ and GABA binding by $14.5 \%$, however, at $100 \mu \mathrm{M}$ picrotoxinin, muscimol binding was inhibited much more than GABA binding ( $48.4 \%$ compared with $25.7 \%$ inhibition). Because of the greater sensitivity of muscimol binding to modulation by barbiturates and picrotoxin, muscimol was used as the radioligand for investigation of caprolactam effects at GABA receptor-ionophore complexes. The structures of the caprolactams studied and their in vivo activities are shown in Table I. The
C4 and C6 methyl-substituted caprolactams (A-F) (Table II) inhibited muscimol binding in a concentration-dependent fashion. Compound $\mathrm{D}$ was the most potent, significantly inhibited binding at $10 \mu \mathrm{M}$. Maximal inhibition by compounds $\mathrm{A}-\mathrm{D}$ and $\mathrm{F}$ was typically $35 \%$; compound $E$ was a less potent inhibitor of muscimol binding (Table II).

The C7 substituted caprolactams (G-J) (Table III) had differing effects upon muscimol binding. While the propyl caprolactam (G) weakly inhibited muscimol binding, the butyl derivative $(H)$ caused little alteration of binding while compounds with larger $\mathrm{C} 7$ substituents (I, J) enhanced muscimol binding at $500 \mu \mathrm{M}$ and above. The $\mathrm{C} 4$ amino substituted caprolactam (K) (Table IV) inhibited muscimol binding and the $\mathrm{C} 4$ allyl ether substituted caprolactam (L) enhanced binding, although its triple bonded analogue (M) lacked activity. Both the C3 substituted 4-oxo caprolactams (N) and (O) enhanced muscimol binding.

The effects of chloride ions were studied upon GABA receptor modulation by picrotoxin, pento-

TABLE II

Inhibition of muscimol binding by convulsant C4 or C6 methyl-substituted caprolactams

Data shown are means \pm S.E.M. of control muscimol binding, 8-12 determinations on 2 or 3 separate membrane preparations. n.t., not tested.

\begin{tabular}{|c|c|c|c|c|c|c|}
\hline \multirow{2}{*}{$\begin{array}{l}\text { Concentration } \\
(\mu M)\end{array}$} & \multicolumn{6}{|l|}{ Caprolactam } \\
\hline & $A$ & $B$ & $C$ & $D$ & $E$ & $F$ \\
\hline 10 & n.t. & $98.4 \pm 3.5$ & n.t. & $89.5 \pm 1.1^{b}$ & n.t. & $93.5 \pm 0.5^{\mathrm{a}}$ \\
\hline 50 & $101.3 \pm 4.5$ & $89.2 \pm 2.9^{a}$ & $93.3 \pm 1.3^{\mathrm{a}}$ & $80.1 \pm 0.8^{h}$ & n.t. & $79.6 \pm 1.6^{b}$ \\
\hline 100 & $85.0 \pm 0.9^{b}$ & $80.4 \pm 2.9^{b}$ & $86.7 \pm 1.7^{b}$ & $72.1 \pm 1.1^{b}$ & $95.6 \pm 2.2$ & $78.0 \pm 1.0^{\mathrm{b}}$ \\
\hline 500 & $76.5 \pm 0.5^{b}$ & $73.7 \pm 2.4^{b}$ & $73.7 \pm 0.9^{b}$ & $65.3 \pm 1.1^{b}$ & $90.0 \pm 2.2^{\mathrm{a}}$ & $70.0 \pm 0.6^{b}$ \\
\hline 1000 & $68.9 \pm 0.8^{b}$ & $65.6 \pm 5.5^{b}$ & $66.3 \pm 0.9^{b}$ & $64.2 \pm 1.4^{b}$ & $88.7 \pm 1.1^{b}$ & $62.4 \pm 0.8^{\mathrm{b}}$ \\
\hline 2000 & $67.1 \pm 0.8^{\mathrm{h}}$ & $66.7 \pm 2.0^{b}$ & $63.9 \pm 1.4^{b}$ & $69.9 \pm 3.1^{b}$ & n.t. & $66.8 \pm 2.9^{b}$ \\
\hline
\end{tabular}

a $P<0.02$; b $P<0.001$ from paired control incubations, Student's 2-tailed $t$-test.

TABLE III

Effects of C7 substituted caprolactams on muscimol binding

Legend and footnotes as for Table II.

\begin{tabular}{|c|c|c|c|c|}
\hline \multirow{2}{*}{$\begin{array}{l}\text { Concentration } \\
(\mu M)\end{array}$} & \multicolumn{3}{|l|}{ Caprolactam } & \multirow[b]{2}{*}{$J$} \\
\hline & $G$ & $H$ & $l$ & \\
\hline 100 & $96.7 \pm 1.1$ & $97.5 \pm 1.7$ & $107.6 \pm 2.8$ & $103.2 \pm 2.5$ \\
\hline 500 & $91.2 \pm 0.9^{a}$ & $106.0 \pm 1.3$ & $123.9 \pm 3.1^{\mathrm{b}}$ & $122.6 \pm 2.8^{\mathrm{b}}$ \\
\hline 1000 & $85.9 \pm 1.3^{b}$ & $104.7 \pm 1.0$ & $136.2 \pm 3.7^{b}$ & $135.4 \pm 7.6^{\mathrm{a}}$ \\
\hline 2000 & $83.1 \pm 1.6^{b}$ & n.t. & $146.4 \pm 6.7^{b}$ & $133.1 \pm 10.3^{a}$ \\
\hline
\end{tabular}


TABLE IV

Effects of various $C 3$ or $C 4$ substituted C6 dimethyl-caprolactams on muscimol binding

Legend and footnotes as for Table II.

\begin{tabular}{|c|c|c|c|c|c|}
\hline \multirow{2}{*}{$\begin{array}{l}\text { Concentration } \\
(\mu M)\end{array}$} & \multicolumn{5}{|l|}{ Caprolactam } \\
\hline & $K$ & $L$ & $M$ & $N$ & $O$ \\
\hline 100 & $94.7 \pm 2.4$ & $101.5 \pm 1.6$ & $105.9 \pm 2.0$ & $100.6 \pm 3.5$ & $105.0 \pm 0.6$ \\
\hline 500 & $81.1 \pm 3.3^{\mathrm{b}}$ & $114.5 \pm 1.6^{b}$ & $99.7 \pm 5.8$ & $107.9 \pm 3.6$ & $122.6 \pm 3.4^{b}$ \\
\hline 1000 & $78.0 \pm 1.1^{\mathrm{b}}$ & $130.4 \pm 1.2^{b}$ & $104.1 \pm 2.5$ & $132.5 \pm 2.0^{\mathrm{b}}$ & $136.0 \pm 5.4^{b}$ \\
\hline 2000 & $67.6 \pm 2.9 \mathrm{~b}$ & $142.7 \pm 7.5^{b}$ & $107.3 \pm 3.4$ & $129.8 \pm 10.4$ & $192.9 \pm 8.1^{\mathrm{b}}$ \\
\hline
\end{tabular}

TABLE $V$

Effects of chloride ions upon the modulation of muscimol/GABA binding by picrotoxinin, pentobarbitone and caprolactams

Drug concentrations shown are micromolar.

\begin{tabular}{|c|c|c|c|c|c|}
\hline & \multicolumn{2}{|l|}{ Inhibitors } & & \multicolumn{2}{|l|}{ Enhancers } \\
\hline \multicolumn{3}{|c|}{ Picrotoxinin } & \multicolumn{3}{|c|}{ Pentobarbitone* } \\
\hline 50 & $51.6 \pm 0.9$ & $82.5 \pm 7.6^{a}$ & 400 & $167.9 \pm 1.8$ & $115.8 \pm 5.7^{b}$ \\
\hline 100 & $51.6 \pm 1.3$ & $76.9 \pm 0.5^{b}$ & 800 & $180.1 \pm 5.1$ & $128.8 \pm 3.0^{\mathrm{b}}$ \\
\hline 500 & $65.3 \pm 1.1$ & $79.6 \pm 1.2^{b}$ & 1000 & $135.4 \pm 7.6$ & $107.8 \pm 1.5^{b}$ \\
\hline 1000 & $64.2 \pm 1.4$ & $77.8 \pm 1.9^{b}$ & 2000 & $133.1 \pm 10.3$ & $100.4 \pm 1.1^{\mathrm{a}}$ \\
\hline
\end{tabular}

a $P<0.02$; $P<0.001$ from chloride containing media, Student's 2 -tailed $t$-test.

* Data for pentobarbitone are for GABA binding (from Skerritt et al. ${ }^{18}$ ). Other data are for muscimol binding.

barbitone and certain caprolactams (Table V). Inhibition of muscimol binding by picrotoxinin (10-100 $\mu \mathrm{M})$ and caprolactam (D) $(100-1000 \mu \mathrm{M})$ was largely, but not totally, dependent upon the presence of chloride ions. Although moderately high concentrations of both compounds inhibited binding in the absence of chloride ions, significantly more inhibition of muscimol binding occurred in the presence of chloride.

As previously demonstrated 18 enhancement of GABA binding by pentobarbitone was highly dependent on chloride ions. Similar results were seen with the depressant caprolactam (J) which enhanced muscimol binding weakly (at only one concentration) in the absence of chloride ions. The GABA antagonist, bicuculline methochloride (BMC) fully inhibited muscimol binding both in the presence and absence of chloride ions. BMC was, however, a more potent inhibitor in the presence of chloride ions (chloride free, $\mathrm{IC}_{50}=14.8 \pm 0.6 \mu \mathrm{M} ; 120 \mathrm{mM}$ chlo- ride ions, $\mathrm{IC}_{50}=5.2 \pm 0.4 \mu \mathrm{M}$ data from two paired experiments performed in quadruplicate on separate TABLE VI

Effects of caprolactams on [ ${ }^{35}$ SITBPS binding

Values are means \pm S.E. of quadruplicate determinations.

\begin{tabular}{lc}
\hline Caprolactam $(500 \mu M)$ & $\%$ Control binding \\
\hline A & $13 \pm 1^{*}$ \\
B & $9 \pm 1^{*}$ \\
C & $8 \pm 1^{*}$ \\
D & $2 \pm 1^{*}$ \\
E & $33 \pm 1^{*}$ \\
F & $3 \pm 1^{*}$ \\
G & $38 \pm 1^{*}$ \\
H & $73 \pm 3^{*}$ \\
I & $67 \pm 2^{*}$ \\
J & $85 \pm 2^{*}$ \\
K & $46 \pm 2^{*}$ \\
L & $94 \pm 3$ \\
M & $108 \pm 1$ \\
N & $86 \pm 2^{*}$ \\
O & $106 \pm 4$ \\
\hline
\end{tabular}

* $P<0.001$ by Student's $t$-test different from control values. 


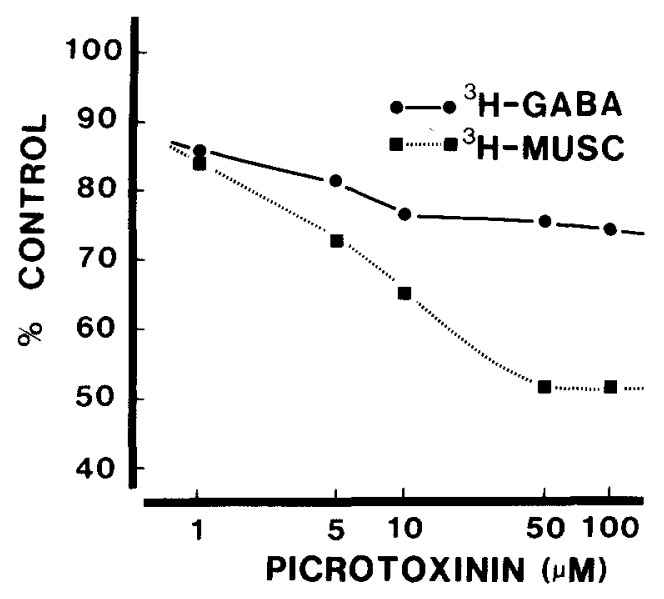

Fig. 2. Inhibition of GABA and muscimol binding by picrotoxinin. Data shown are from 4 experiments performed in quadruplicate on separate membrane preparations. Standard errors did not exceed the size of the symbols used.

membrane preparations).

Most of the caprolactams inhibited [ ${ }^{35} \mathrm{~S}$ ]TBPS binding at $500 \mu \mathrm{M}$ as indicated in Table VI. None significantly enhanced $\left[{ }^{35} \mathrm{~S}\right] \mathrm{TBPS}$ binding under conditions where diazepam clearly enhanced such binding ${ }^{20}$. There was a direct correlation (correlation coefficient $0.89, P<0.0001$ ) between caprolactam effects at $500 \mu \mathrm{M}$ on TBPS binding (Table VI) and on muscimol binding in the presence of chloride ions (Tables I-III). The two most potent inhibitors of TBPS binding, caprolactams (D) and (F) had $\mathrm{IC}_{50}$

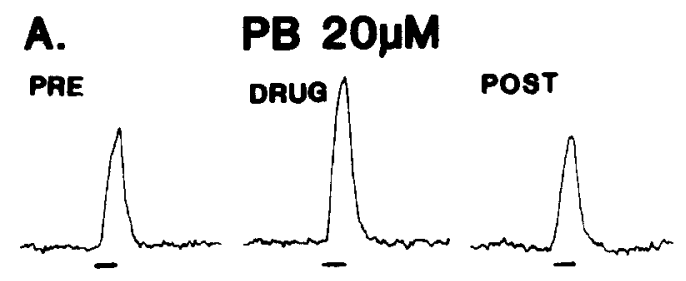

B. PTX $100 \mu \mathrm{M}$

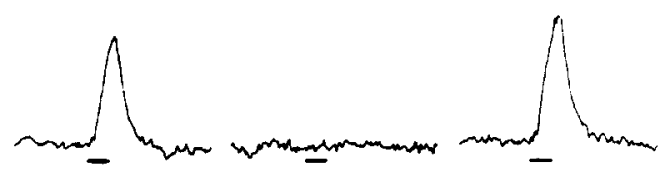

values of $5.7 \pm 0.5 \mu \mathrm{M}$ and $17.2 \pm 1.3 \mu \mathrm{M}$, respectively, and were thus significantly less potent than picrotoxinin, $\mathrm{IC}_{50} 0.22 \pm 0.02 \mu \mathrm{M}$.

The effects of compounds (D) (4,4,6,6-tetramethylhexahydro-2H-azepin-2-one) and (O) (3,3-diallyl6,6-dimethylhexahydro-2H-azepin-2,4-dione), the most potent inhibitor and enhancer of muscimol binding, respectively, were assessed upon the responses of mouse spinal cord neurones in dissociated cell culture to iontophoretically applied GABA, and their effects compared with those of picrotoxin and pentobarbitone. In 5 cells, compound (D) inhibited GABA responses by $41.8 \pm 4.3 \%$ (mean \pm S.E.M.) at $100 \mu \mathrm{M}$ and by $66.4 \pm 3.0 \%$ at $500 \mu \mathrm{M}$. Picrotoxin $(100 \mu \mathrm{M})$ abolished $\mathrm{GABA}$ responses completely in all 4 cells tested (Fig. 3). Caprolactam (O) failed to alter GABA responses at $100 \mu \mathrm{M}$ (response $102.8 \pm$ $2.1 \%$ control, 4 cells) but at $1 \mathrm{mM}$ enhanced GABA responses in every cell tested (response $114.2 \pm$ $1.5 \%$ control, 5 cells). Pentobarbitone $(20 \mu \mathrm{M})$ enhanced GABA responses by $43.1 \pm 4.0 \%$ ( 6 cells).

Caprolactam (D) produced spontaneous paroxysmal depolarizing events or repeated bursts of firing, (grade 4 or 5 activity ${ }^{9}$ ) in $60 \%$ ( 9 of 15 ) of cells studied, while only $27 \%$ ( 3 of 11 ) of cells in control medium displayed such activity. Although none of the cells under control conditions were quiescent (i.e. lacking spontaneous action potentials), in the presence of $1 \mathrm{mM}$ caprolactam (O), 7 of 9 cells (78\%)

\section{CAPRO $11 \mathrm{mM}$}
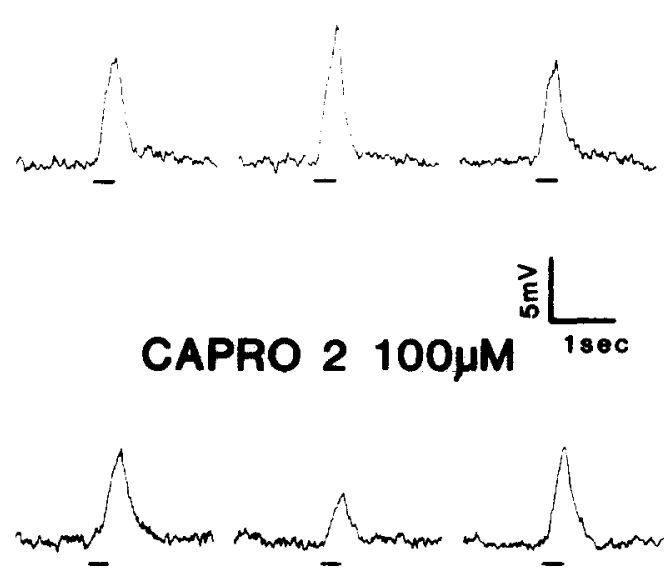

Fig. 3. Effects of caprolactams, pentobarbitone and picrotoxin upon GABA responses of mouse spinal cord neurones in culture. A: pentobarbitone, $\mathrm{PB}(20 \mu \mathrm{M})$ and caprolactam $(\mathrm{O})(\mathrm{CAPRO} 1)$ enhanced $\mathrm{GABA}$ responses (cell membrane potentials $=-75$ and -80 $\mathrm{mV})$. B: inhibition of GABA responses by picrotoxin. PTX $(100 \mu \mathrm{M})$ and caprolactam (D) (CAPRO 2) in separate neurones (cell membrane potentials $=-85$ and $-85 \mathrm{mV}$ ). 


\section{A. CONTROL}
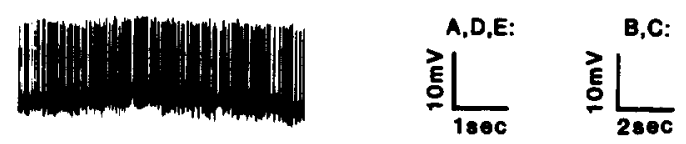

B. PB $500 \mu \mathrm{M}$

C. CAPRO $11 \mathrm{mM}$

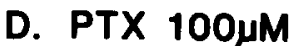

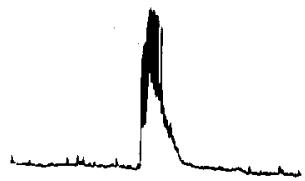

Fig. 4. Effects of caprolactams, pentobarbitone and picrotoxin upon spontaneous neuronal activity. A: spontaneous activity pattern in a 'control' cell. B: pentobarbitone, $\mathrm{PB}(500 \mu \mathrm{M})$, and (C) caprolactam (O) (CAPRO 1) (1 mM) produced neuronal quiescence in most cells. D: picrotoxin, PTX $(100 \mu \mathrm{M})$ and caprolactam (E) (CAPRO 2) $(500 \mu \mathrm{M})$. Membrane potentials of all cells were between -50 and $-60 \mathrm{mV}$.

were quiescent. In the presence of compound $(\mathrm{O})$, intracellular injection of depolarizing current could still evoke repetitive firing of action potentials. Further, cell membrane potentials were not depolarized in the presence of either caprolactam. It is thus unlikely that the caprolactam effects arise simply from toxicity. Pentobarbitone $(500 \mu \mathrm{M})$ produced quiescence in all 6 cells studied, as earlier noted 15 , while picrotoxin $(100 \mu \mathrm{M})$ produced paroxysmal depolarizing events in all 4 cells studied.

\section{DISCUSSION}

The finding that pentobarbitone enhancement and picrotoxinin inhibition of GABA receptor binding are more pronounced when muscimol rather than GABA is used as the radioligand may suggest that GABA and muscimol interact somewhat differently with GABA receptor-ionophore complexes. While chloride-dependent enhancement of GABA receptor binding has been demonstrated for a variety of labelled GABA receptor ligands ${ }^{12}$, full barbiturateconcentration response curves for $\left[{ }^{3} \mathrm{H}\right] \mathrm{GABA}$ and $\left[{ }^{3} \mathrm{H}\right]$ muscimol binding have not previously been de-' scribed within the one study. It is possible, however, that the apparent greater maximal enhancement of muscimol binding compared with GABA binding is the result simply of differing fractional binding site occupancies by the two radioligands. However, since pentobarbitone increases the density rather than the affinity of high affinity muscimol or GABA binding under the experimental conditions used 18,22 this interpretation is unlikely.

In independent studies Olsen and Snowman ${ }^{11}$ found that high concentrations of picrotoxin $(30 \mu \mathrm{M})$ inhibited GABA binding by about $25 \%$ while others $^{8,22}$ found that similar picrotoxin or picrotoxinin concentrations inhibited muscimol binding by about $50 \%$. We have confirmed these results by performing paired experiments with picrotoxinin on GABA and muscimol binding in several membrane preparations formed on different occasions. Other evidence exists that muscimol and GABA do not label identical populations of sites in brain membranes. Muscimol labels only one subclass of binding sites while GABA labels two populations in washed synaptosomal membranes ${ }^{16}$. Unlike pentobarbitone, diazepam was a more potent enhancer of GABA than of muscimol binding. Since pentobarbitone and picrotoxinin are thought to act on or near GABA receptor coupled chloride channels it may be possible that muscimol labels a subclass of GABA receptors closely associated with GABA-coupled chloride channels.

The C4 and C6 methyl substituted caprolactams are potent convulsants (Table I) and like picrotoxinin inhibited muscimol binding potently, but only partially (Table II). That the inhibition was partial was confirmed by the observation that $2 \mathrm{mM}$ of compounds $(\mathrm{A}-\mathrm{F})$ did not inhibit binding any more than $1 \mathrm{mM}$ of each particular caprolactam. Compounds (D) and (F) are the most potent inhibitors of muscimol binding, while compound (E), a relatively weak convulsant, was a relatively weak inhibitor.

The good quantitative correlation between the effects of the caprolactams on TBPS binding and on muscimol binding in the presence of chloride ions indicate that the caprolactams are influencing binding to GABA agonist recognition sites and to antagonist sites associated with chloride channels in a similar manner. The appreciably greater potency of the caprolactams against TBPS binding indicate a closer association of their direct site of action with the chlo- 
ride channels than with the GABA agonist recognition sites. Thus the influence of caprolactams on muscimol binding is relatively weak compared to that of direct acting GABA agonists and furthermore requires the presence of chloride ions.

There is a reasonable qualitative correlation between in vivo activity and the nature of muscimol binding modulation for the $\mathrm{C} 7$ substituted caprolactams. The convulsant propyl compound $(G)$ inhibited binding, while the depressants ( $\mathrm{I}$ and $\mathrm{J}$ ) enhanced muscimol binding. Caprolactam $(\mathrm{H})$, a weak depressant, was inactive at $1 \mathrm{mM}$. No enhancement of TBPS binding was observed at the single concentration of caprolactam tested, but the caprolactams which enhanced muscimol binding were all relatively weak inhibitors of TBPS binding.

The relationship between behavioural activity and binding was less obvious for the remaining compounds $(\mathrm{K}-\mathrm{O})$. Caprolactam $(\mathrm{K})$, a depressant, inhibited binding, but with an amino substituent it is possible that it inhibits binding at the muscimol recognition site. The other compounds had complex in vivo activities, for example compound $(\mathrm{O})$ is a convulsant but produces muscle paralysis at similar doses. This compound however, markedly enhanced GABA binding. With the possible exception of $(\mathrm{K})$ it is unlikely that the caprolactams act directly upon GABA receptor recognition sites. Like picrotoxin and pentobarbitone, the modulatory effects of the convulsant and the depressant caprolactam tested were largely chloride-dependent. The partial nature of inhibition was different from that of bicuculline methochloride (BMC) which fully inhibited muscimol binding. BMC was more potent in the presence of chloride ions, as earlier noted ${ }^{22}$, which may suggest that GABA agonists and antagonists interact with GABA recognition sites differently.

The behaviour of the caprolactams in the electrophysiological assays corresponded to their behaviour in the binding assays. Compound (D), which showed picrotoxin-like inhibition of muscimol and TBPS binding, inhibited GABA responses on spinal cord neurones in culture and produced spontaneous par- oxysmal depolarizing events. In contrast, compound $(O)$, which enhanced muscimol binding without influencing TBPS binding, enhanced GABA responses and like pentobarbitone produced quiescence in spinal cord neurones. Unfortunately, due to vehicle sensitivity of the electrophysiological assays, the effects of caprolactam with clear depressant activity in vivo (such as I or J) could not be investigated. Earlier studies using extracellular recording from the substantia nigra in vivo had demonstrated GABA antagonist activity for compounds (B) and (C), following intravenous injection ${ }^{7}$ however the site of action of the caprolactams could not be determined in that study. The caprolactams appear to be relatively selective in that compounds (C), (G) and (K) $(100 \mu \mathrm{M})$ did not inhibit the uptake of GABA on L-glutamate by rat brain slices (Johnston, unpublished) although some caprolactams at high concentrations inhibit the binding of diazepam to brain membranes (Davies and Skerritt, unpublished).

For the relatively simple $\mathrm{C} 4$ and $\mathrm{C} 6$ methyl substituted and $\mathrm{C} 7$ alkyl substituted caprolactams (A-J) there appears to be a direct relationship between their behavioural effects (convulsant or depressant) and their effects upon muscimol binding (inhibition or enhancement). This is in contrast to barbiturate effects upon GABA binding. While a correlation between relative anaesthetic potency and relative GABA binding enhancement exists for sedative barbiturates ${ }^{18}$, both sedative and convulsant barbiturates enhance GABA binding 11,18.25. The relatively simple caprolactam molecular structure may provide another useful tool for the investigation of GABAcoupled channels and their modulation.

\section{ACKNOWLEDGEMENTS}

The authors are grateful to the National Health and Medical Research Council of Australia, the Australian Research Grants Scheme and the US National Science Foundation for financial support. J.H.S. was the recipient of an award from the Rotary Foundation of Rotary International. 


\section{REFERENCES}

1 Asano, T. and Ogasawa, N., Chloride dependent stimulation of GABA and benzodiazepine receptor binding by pentobarbitone, Brain Rèsearch, 225 (1981) 212-216.

2 Duong, T., Prager, R. H., Tippet, J. M., Ward, A. D. and Kerr, D. I. B., Central nervous system active compounds. II. The synthesis of some 4-, 5-, 6- and 7-substituted caprolactams, Aust. J. Chem., 29 (1976) 2667-2682.

3 Elison, C., Lien, E. J., Zinger, A. P., Hussain, M., Tong, G. L. and Golden, M., CNS activities of lactam derivatives, J. Pharm. Sci., 60 (1971) 1058-1062.

4 Enna, S. J. and Snyder, S. H., Properties of gamma-aminobutyric acid (GABA) receptor binding in rat brain synaptic membrane fractions, Brain Research, 100 (1975) 81-97.

5 Hutchison, G. I., Prager, R. H. and Ward, A. D., Central nervous system active compounds. III. The synthesis of 4and 6-substituted caprolactam derivatives by the Schmidt and Beckman rearrangements, Aust. J. Chem., 33 (1980) 2477-2486.

6 Johnston, G. A. R., Allan, R. D. and Skerritt, J. H., GABA receptors, Handbk. Neurochem., 6 (1983) 213-237.

7 Kerr, D. I. B., Dennis, B. J., Breuker, E. L. M., Prager, R. H., Ward, A. D. and Duong, T., Antagonism of GABAmediated inhibition in the central nervous system by caprolactam derivatives, Brain Research, 110 (1976) 413-416.

8 Matsumoto, K. and Fukada, H., Anisatin modulation of temperature-dependent inhibition of $\left[{ }^{3} \mathrm{H}\right]$ muscimol binding by chloride ion, Brain Research, 270 (1983) 103-108.

9 McLean, M. J. and Macdonald, R. L., Multiple actions of phenytoin on mouse spinal cord neurons in cell culture, $J$. Pharmac. exp. Therap., 227 (1983) 779-789.

10 Mooney, B. A., Prager, R. H. and Ward, A. D., Central nervous system active compounds. V. Claisen rearrangement products of allyl vinyl ethers obtained from caprolactam derivatives, Aust. J. Chem., 33 (1980) 2717-2728.

11 Olsen, R. W. and Snowman, A. M., Chloride dependent enhancement by barbiturates of gamma-aminobutyric acid receptor binding, J. Neurosci., 2 (1982) 1812-1823.

12 Nowak, L. H., Young, A. B. and Macdonald, R. L., GABA and bicuculline actions on mouse spinal cord and cortical neurons in cell culture, Brain Research, 244 (1982) 155-164.

13 Quast, V. and Brenner, O., Modulation of $\left[{ }^{3} \mathrm{H}\right]$ muscimol binding in rat cerebellar and cerebral cortical membranes by picrotoxin, pentobarbitone and etomidate, J. Neurochem., 41 (1983) 418-425.

14 Ransom, B. R., Neale, E., Henkart, M., Bullock, P. N. and Nelson, P. G., Mouse spinal cord cells in culture. I. Morphologic and intrinsic neuronal electrophysiological properties, J. Neurophysiol., 40 (1977) 1132-1150.

15 Schulz, D. W. and Macdonald, R. L., Barbiturate enhancement of GABA-mediated inhibition and activation of chloride ion conductance: correlation with anticonvulsant and anesthetic actions, Brain Research, 209 (1981) 177-188.

16 Skerritt, J. H. and Johnston, G. A. R., Diazepam stimulates the binding of GABA and muscimol but not THIP to rat brain membranes, Neurosci. Lett., 38 (1983) 315-320.

17 Skerritt, J. H., Willow, M. and Johnston, G. A. R., Diazepam enhancement of low affinity GABA binding to rat brain membranes, Neurosci. Lett., 29 (1982) 63-66.

18 Skerritt, J. H., Johnston, G. A. R., Katsikas, T., Tabar, J., Nicholson, G. H. and Andrews, P. R., Actions of pentobarbitone and derivatives with modified 5-butyl substituents on GABA and diazepam binding to rat brain synaptosomal membranes, Neurochem. Res., 8 (1983) 1337-1350.

19 Squires, R. F., Cadisa, J. E., Richardson, M. and Saederup, E., $\left.{ }^{35} \mathrm{~S}\right] \mathrm{t}-\mathrm{Butylbicyclophosphothionate}$ binds with high affinity to brain specific sites coupled to $\gamma$-aminobutyric acid-A and ion recognition sites, Molec. Pharmacol., 23 (1983) 326-336.

20 Supavilai, P. and Karobath, M., Differential modulation of [ ${ }^{35}$ S]TBPS binding by the occupancy of benzodiazepine receptors with its ligands, Europ. J. Pharmacol., 91 (1983) 145-146.

21 Supavilai, P., Mannonen, A., Collins, J. F. and Karobath, M., Anion-dependent modulation of ${ }^{3} \mathrm{H}$-muscimol binding and of GABA stimulation of ${ }^{3} \mathrm{H}$-flunitrazepam binding by picrotoxin and related CNS convulsants, Europ. J. Pharmacol., 81 (1982) 687-691.

22 Supavilai, P., Mannonen, A. and Karobath, M., Modulation of GABA binding sites by CNS depressants and CNS convulsants, Neurochem. Int., 4 (1982) 259-268.

23 Thyagarajan, R., Ramanjaneyulu, R. and Ticku, M. K., Enhancement of diazepam and gamma-aminobutyric acid binding by $(+)$-etomidate and pentobarbitone, J. Neurochem., 41 (1983) 578-585.

24 Whittle, S. R. and Turner, A. J., Differential effects of sedative and anticonvulsant barbiturates on specific $\left[{ }^{3} \mathrm{H}\right]-$ GABA binding to membrane preparations from rat brain cortex, Biochem. Pharmacol., 18 (1982) 2891-2895.

25 Willow, M. and Johnston, G. A. R., Enhancement by anaesthetic and convulsant barbiturates of GABA binding to rat brain synaptosomal membranes, J. Neurosci., 1 (1981) 364-367. 